\title{
AN IGNORED ARGUMENT FOR SCIENTIFIC REALISM**
}

\begin{abstract}
Why believe in scientific realism? The answer that overwhelms the mainstream debate is "the nomiracles argument" (NMA): realism best explains the observational success of scientific theories. Yet more than thirty years ago another argument was proposed by Smart, Devitt, Glymour, McMullin, and Salmon and called "the basic argument" (BA) by Devitt: realism best explains the observed phenomena. Rather than having been addressed and assessed since, BA has been almost entirely ignored. The paper carefully distinguishes BA from NMA and argues that whereas NMA is dubious, BA is good. Why has BA been ignored? Experience suggests that philosophers may find it too close to science and mistakenly hanker after a "more philosophical" justification for realism. No such justification is needed or desirable.
\end{abstract}

Keywords: scientific realism, no-miracles argument, observational success, explanatory success, basic argument, abduction

Why believe in scientific realism? The answer that overwhelms the mainstream debate is: "the no-miracles argument" (NMA), also known as "the success argument" and "the ultimate argument." In slogan form, NMA claims that realism best explains the observational success of scientific theories. NMA has been the focus of criticism from those who are, at least, dubious of realism. But, as we shall see, there is another argument that appeared independently in several places more than thirty years ago (Smart 1982,

* Graduate Center, City University of New York, 365 Fifth Avenue, New York, NY 10016, USA, e-mail: MDevitt@gc.cun.edu, ORCID: https://orcid.org/oooo-0oo3-2298-2490.

** This paper arose out of papers given at various places and with various titles, beginning with a paper at the Cape Town conference, New Thinking about Scientific Realism, August 2014. I am grateful for comments at these meetings and on drafts. I am particularly indebted to the following for written comments that led to changes: Amanda Bryant, Greg Frost-Arnold, Peter Godfrey-Smith, Michael Levin, Robert Nola, David Pereplyotchik, Graham Priest, Georges Rey, Iakovos Vasiliou. 
Devitt 1984, Glymour 1984, McMullin 1984, Salmon 1984). In slogan form, this argument claims that realism best explains the observed phenomena. I favored this argument, calling it "the basic argument" (BA). Rather than having been addressed and assessed, BA has been almost entirely ignored. Perhaps the significance of its differences from NMA seems too subtle to bother with. I myself did not make much of them and also urged NMA despite them (Devitt 1984, 2005). I now think that this was a mistake. In this paper, I will attempt to show why. The differences between the two arguments are in fact very significant: in particular, BA is a good argument for realism, NMA is a dubious one. ${ }^{1}$ I shall also argue that NMA, unlike BA, is at the wrong level, at a "philosophical" level above science.

The argument for this is in sections 6 and 7. Before that, we need to be clear about what scientific realism is (section 1); about what precisely NMA and BA are, how they differ (section 2), and how realism could explain either observational success or the observed phenomena (section 3); about abduction (section 4); and about the origins of BA and how it has been ignored (section 5).

Why has BA been ignored? Well, the significance of its differences from NMA is subtle. Aside from that, my experience suggests that philosophers find BA too close to science, "not philosophical enough," to be interesting. So where I criticize NMA for being at a level above science, I think that philosophers ignore BA because it is not: they hanker after a justification for realism from outside science. This hankering is a mistake (section 7 ).

So I will be mainly arguing for five theses:

I. BA differs from NMA.

II. NMA and BA are "wholesale" arguments for realism inheriting their power from "retail" arguments.

III. $\quad$ BA was urged more than thirty years ago but has been almost entirely ignored.

IV. NMA is dubious but BA is good: so the difference between them is significant.

V. A meta-scientific "philosophical level” argument for realism like NMA is neither needed nor desirable.

\footnotetext{
${ }^{1}$ However, I am not convinced by a popular criticism (in, e.g., Magnus, Callender 2004) that NMA commits "the base-rate fallacy."
} 
In arguing for these theses, I will of course be describing BA and why it is good but, I emphasize, I will not be adding to the case for it that has already been made. Nor will I be defending it from familiar antirealist objections.

\section{DEFINING SCIENTIFIC REALISM}

What is scientific realism? The literature provides a bewildering variety of answers. I shall draw on my lengthy discussions elsewhere (Devitt 1984, 2005) in describing what I take to be the core doctrine that NMA and BA are supposed to justify.

Taken literally, scientific theories are committed to the existence of many unobservable entities and to those entities having certain properties. The central idea of scientific realism is that science really is committed and is typically right in its commitments. So, typically, those unobservable entities exist and have those properties. I call this the "existence dimension" of realism. This realist view is rejected by those who are skeptical of the picture of reality that we get from science. Realism also has what I call an "independence dimension": the entities of science are mind-independent in that they do not depend for their existence and natures on the cognitive activities and capacities of our minds. This dimension is opposed by constructivists like Thomas Kuhn. NMA and BA are offered in support of the existence dimension of scientific realism. So we can set the independence dimension aside in defining the doctrine that concerns us here. ${ }^{2}$

The existence dimension could do with some clarification. First, what is meant by "scientific theories"? Given the concerns of NMA and BA, the answer is current scientific theories. Second, the qualification "typically" is necessary because current scientific theories are surely making some mistakes. Third, we seem to need a further qualification in light of the fact that scientists themselves have many epistemic attitudes to their theories: thus, some theories are known to be false but are thought useful for predictions; judgment is suspended on exciting speculations at the frontiers; strong commitment is restricted to thoroughly tested and well-established theories. The realist's commitment is only to the claims of the latter theories, which I shall briefly call "well-established." Finally, realism may not always go along with the scientific posit of an unobservable because there may be good reasons for thinking that our explanatory needs do not require the posit. We can briefly capture this

\footnotetext{
${ }^{2}$ I have discussed Kuhn and constructivism elsewhere in arguing for the independence dimension (Devitt 1984, 2001, 2010).
} 
critical aspect of realism by saying that realism is committed only to "essential" unobservables. So, the existence dimension of realism is a cautious and critical summary of the commitments of well-established current theories.

There is room for much more clarification, of course, but I think this is enough for our purposes. We can now define, well enough, two doctrines of scientific realism that concern NMA and BA, an "entity" realism (SR) and a stronger "fact" realism (SSR):3

SR: Typically, the essential unobservables of well-established current scientific theories exist.

SSR: Typically, the essential unobservables of well-established current scientific theories exist and have approximately the properties attributed to them by the theories.

SR and SSR are about what the world is like and so are obviously metaphysical, not semantic. Some realism definitions using the terms "refer" or "true" may appear to be semantic but are not really so. For these definitions are just exploiting the "disquotational" properties of these terms and so do not differ significantly from the likes of SR and SSR;4 for example, we can come close to paraphrasing SSR with: "Typically, well-established current scientific theories positing unobservables are approximately true." However, there are other definitions that do differ significantly because they really have a semantic component. Not long ago it was common to take "scientific realism" to refer to some combination of a metaphysical doctrine like SSR with a correspondence theory of truth often explained with the help of causal theories of reference. 5 This is an odd combination of doctrines. The scientific realist's main concern is to rebut skepticism about the unobservable world. The nature of truth is surely an important issue, but it has little, if anything, to do with that skepticism and is not relevant to the realism that NMA and BA argue for.

3 There is also the weaker "structural" realism (Worrall 1989) which has no commitment to the entities of science.

${ }^{4}$ Nor do some epistemic definitions differ significantly from the metaphysical ones; indeed, they are parasitic on them (Devitt 2005/2010: 70-71).

5 See, e.g., Putnam 1978: 18-20, 123-125; 1987: 15-16, Fine 1986a: 115-116, 136-137, Miller 1987, Kitcher 1993: 127-133, Brown 1994. Arthur Fine dismisses the realism issue altogether because he takes it to involve an issue about truth. Despite this dismissal, Fine urges the mysterious "Natural Ontological Attitude" (1986a, b), which often seems to be a realist doctrine like SSR. However, some passages (1986b: 163-165) make it hard to take Fine as a realist. The introduction of theories of truth into the definition of scientific realism followed a trend in definitions of realism generally. Michael Dummett (1978) has been particularly influential in this. 
With scientific realism understood along the lines of SR and SSR, I turn to describing and comparing NMA and BA.

\section{THESIS I: BA DIFFERS FROM NMA}

NMA: Well-established current scientific theories are successful in that their observational predictions tend to come out true: or, "disquoting," if such a theory says that $S$, then the world tends to be observationally as if $S$. Why are these theories thus successful? The slogan form of NMA's answer is: realism explains the observational success. Moving beyond the slogan, the best explanation of the success is said to be that the theories' theoretical terms typically refer (SR), and the theories are typically approximately true (SSR); or, "disquoting," typically, the world is observationally as if $S$ because, approximately, $S$. For example, why do the many predictions made by our theory of viruses turn out to be true? Because there really are viruses. Hilary Putnam goes further: it would be "a miracle" that theories were so successful if they weren't typically approximately true (Putnam 1975: 73; 1978: 18-19; hence the name "no-miracles argument"). Realism does not just have the best explanation of success, there can be no other good explanation. ${ }^{6}$

I am here following the standard construal of NMA according to which realism is supposed to explain observational predictive success, but, as Jerry Doppelt notes (2007: 96), there is sometimes a suggestion that realism is supposed to explain explanatory success as well, or perhaps even instead. I shall set aside an NMA that concerns explanatory success until section 7 .

$B A$ : Here is how I introduced BA (as an argument for $\mathrm{SR}$ ):

The basic argument for the unobservable entities is simple. By supposing that they exist, we can give good explanations of the behavior and characteristics of observed entities, behavior and characteristics which would otherwise remain completely inexplicable. (Devitt 1984/1991: 108)

In slogan form, realism explains the observed phenomena. Moving beyond the slogan, the best explanation of the observed phenomena is said to be that the theories' theoretical terms typically refer (SR), and the theories are typically approximately true (SSR). For example, why do some people exhibit certain symptoms? Because there really is a cold virus that has infected them.

\footnotetext{
Clavius.

${ }^{6}$ According to Alan Musgrave (1988), NMA has been around a long time, at least since
} 
I urged both NMA and BA whilst bringing out the difference between the two arguments along the following lines (Devitt 1984/1991: 114, 2005/2010: 78). Where NMA uses realism to explain the observational success of theories, to explain why observed phenomena are mostly in accord with what theories predict, BA uses realism to explain those very phenomena. This is not to say that observational success is unimportant to BA: the explanation of observed phenomena, like any explanation, is tested by its observational success. So NMA and BA have different relations to success: whereas according to NMA realism explains success, according to BA realism is successful. And, to emphasize, BA's argument is that realism explains the phenomena.7

I now note two further differences between BA and NMA. First, if a theory explains certain observed phenomena, it must be observationally successful to the extent of those phenomena, but the reverse is not the case: a theory may predict those phenomena, hence be successful, without explaining them. It is easy to demonstrate this. If $T$, a theory positing unobservables, explains certain observed phenomena, then it will predict those phenomena. In contrast, $T^{*}$, the theory according to which the observational world is as if $T$, will predict those phenomena without explaining them. Ptolemaic astronomy may provide a real example of a theory that predicts what it does not explain.

Second, NMA is an argument at a "philosophical" level above science. It will become clear that BA is not so, in any interesting sense. I shall discuss the significance of this difference in section 7 .

\section{THESIS II: \\ NMA AND BA ARE “WHOLESALE” ARGUMENTS FOR REALISM, INHERITING THEIR POWER FROM “RETAIL” ARGUMENTS}

One might object to NMA along these lines: "It is plausible that the approximate truth of a theory explains its success. But then what is there for realism to explain?" (see, for example, Gauker 2006: 128). I have often heard a similar objection to BA: "It is plausible that the approximate truth of a theory explains certain observed phenomena. But then what is there for realism to explain?" The short answer to these objections is that realism inherits the explanatory power of the theories. Here is a longer answer.

Consider NMA first. It rests on claims about individual theories: that the approximate truth of $T_{1}$ provides the best explanation of why $T_{1}$ is observa-

\footnotetext{
7 Richard Boyd (1984) has offered another argument: realism explains the success of scientific methodology.
} 
tionally successful; that $T_{2}$ does, why $T_{2}$ is; ...; that $T_{n}$ does, why $T_{n}$ is. Now, a realist doctrine like SR and SSR is "a cautious and critical summary of the commitments of well-established current theories," the caution being captured by the talk of what is "typically" the case. Drop that caution for a moment. One might then argue, along the lines of NMA, that this incautious realism best explains the success of theories in general. Whatever strength this argument has, it has simply in virtue of the explanations by individual theories. So this incautious realism would have a different explanandum from any individual theory but would simply inherit its explanatory power from the individual theories. In a sense, it would add nothing new in the way of explanation.

The realism that NMA actually argues for is wisely cautious but similarly inherits its explanatory power from the individual theories. SR and SSR talk cautiously of what is "typically" the case because well-established current theories probably include some mistakes. Although we are entitled to believe each of the theories $T_{1}$ to $T_{n}$ on the basis of inferences to the best explanation, when contemplating their combination, we realize that probably some of the theories are false; those inferences are fallible; sometimes the success of a theory will not be explained by its approximate truth. (We are in the same epistemic position as the author of a book who apologizes in the preface for the errors that she has likely made in the book.) Still the caution does not alter the main point: the claim that the approximate truth of theories typically explains their success inherits its explanatory power from individual theories.

The objection to BA has an analogous answer. BA also rests on claims about individual theories: that the approximate truth of $T_{1}$ best explains observed phenomenon $P_{1} ; T_{2}, P_{2} ; \ldots ; T_{n}, P_{n}$. It is in virtue of these explanations by individual theories that SR and SSR best explain a whole range of observed phenomena. So, once again, SR and SSR have a different explanandum from any individual theory but simply inherit their explanatory power from the individual theories. In a sense, SR and SSR add nothing new in the way of explanation. ${ }^{8}$ Ernan McMullin has put the point nicely:

one may generalize from the fact that so many scientific theories support realist claims. ... But if one does this, ... one must be careful not to suggest that this is somehow an autonomous and cogent argument in its own right, independent of the issue as it arises for specific theories. (1991: 106)

P. D. Magnus and Craig Callender (2004) make a neat distinction between "retail" arguments for scientific realism, which concern particular theories, and

\footnotetext{
${ }^{8}$ Actually, they do add something new because, as Robert Nola has reminded me, the conjunction of theories can explain what no theory alone explains. But BA's case for SR and SSR does not depend on that addition.
} 
"wholesale" arguments, which concern science as a whole. NMA and BA are wholesale arguments based on retail arguments. This is very apparent in presentations of BA (see section 5), as the McMullin quote illustrates, but perhaps less so in presentations of NMA. Still, it is important to the assessment of NMA that it also rests on retail arguments.

What sort of retail arguments is BA based on? I shall address this question after we have seen where BA came from in section 5 . This will throw further light on the nature of BA.

\section{ABDUCTION}

NMA and BA exemplify realists' fondness for "inference to the best explanation" or, as it is often called, "abduction." This is obviously not the place for a full discussion of abduction, but three points about it are important to an assessment of NMA and BA.9 I trust that they are relatively uncontroversial. First, despite the talk of inference to the best explanation, abduction does not license the acceptance of the best of a bad lot of explanations of some phenomenon. The explanation accepted should be a good one, and if there are no good ones, then we should simply suspend judgment. So, good abductions rest on good explanations. Second, a good explanation must be plausible given what else we know - it must be plausible relative to background knowledge. Third, to feature in an acceptable abduction a good explanation must of course be better than any actual alternative, but it needs also to be better than any alternative that is likely, given what we already know.

That NMA relies on abduction discredits it in some eyes (e.g., van Fraassen 1980, 1989, Laudan 1981, Fine 1986a). If this were a good objection to NMA, it would be just as good against BA, of course; see section 6 for more on this.

\section{THESIS III: BA WAS URGED MORE THAN THIRTY YEARS AGO BUT HAS BEEN ALMOST ENTIRELY IGNORED}

I proposed BA in the first edition of Realism and Truth (1984). It is also to be found independently in the works of J. J. C. Smart, Ernan McMullin, Clark Glymour, and Wesley Salmon around the same time.

9 See Lipton 1991 for a full discussion. My comments draw on my 2010: 93-94. 
Smart: In introducing my discussion of scientific realism, I mentioned two books by Smart $(1963,1968)$ as "particularly helpful" (Devitt 1984/1991: 108). I recently checked the books and found NMA, including talk of a "cosmic coincidence" (1963: 39; see also 1968: 151), but I did not find BA. However, a later paper by Smart, "Difficulties for Realism in the Philosophy of Science" (1982), cited by Ian Hacking (1983: 54) but otherwise apparently neglected in the literature, has both arguments. Here is its presentation of NMA:

The realist's most general argument against instrumentalism is that he can explain the success of microphysics in predicting facts on the macro-level. The instrumentalist just has to accept this success as a brute fact. . . . something like a cosmic miracle. (Smart 1982: 364).

Smart then contemplates an instrumentalist objection which he describes as follows:

To explain the facts on the macro-level by reference to supposed facts on the microlevel is to treat the former as non-accidental relative to the latter. But will the latter facts not be just as much cosmic coincidences themselves? (Smart 1982: 364).

But notice that the first sentence implies that the instrumentalist is objecting not to the just-stated NMA but rather to BA: what realism, with its reference to micro-level facts, is now taken to be explaining is not the success of the theory but macro-level facts. So Smart seems to be conflating the two arguments.

A little later, Smart raises a question: "the scientific realist looks at the facts on the observational level and asks why they are as they are" (1982: 364265). His answer is as clear a statement of BA as one could want:

by postulating unobservable particles, and so on, and by stating a relatively small number of laws pertaining to these, a scientist can explain the untidy and multifarious facts about the macro-level in a relatively simple and unified manner. (Smart 1982: 365)

There is not a word here about explaining the observational success of theories; it's all about explaining observational facts.

BA is also implicit in most of what follows. But then, near the end, Smart sums up his argument in these words:

Earlier in this paper, I argued that realism was plausible, because it gave the best explanation of the predictive success of physics and because only if there is a realistic theory can we avoid supposing an implausible cosmic coincidence on the observational level. (Smart 1982: 373)

The first half of this sentence is NMA, but the second has at least a hint of BA. I conclude that Smart does indeed have BA, albeit conflated with NMA.

McMullin: In 1984, Jarrett Leplin edited a terrific collection of papers, Scientific Realism. One of those papers is McMullin's, "A Case for Scientific 
Realism" (1984). McMullin finds his case in scientific explanations of observed phenomena. ${ }^{10}$ Giving a range of examples in support (1984: 26-35), McMullin claims:

Scientists construct theories which explain the observed features of the physical world by postulating models of the hidden structure of the entities being studied. This structure is taken to account causally for the observable phenomena. (1984: 27)

This "best case for scientific realism" (McMullin 1984: 26) is BA. What about NMA? McMullin notes that the "case for scientific realism can be made in a variety of ways" but declines to comment on them (1984: 26). In a later article, however, he explicitly distances himself from "the Putnam-Boyd formulation of the case for realism," hence presumably from NMA (1991: 104).

Glymour: Another of the papers in Leplin's collection is Glymour's "Explanation and Realism" (1984). The paper begins:

One way to argue to a theory is to show that it provides a good explanation of a body of phenomena and, indeed, that it provides a better explanation than does any available alternative theory. (Glymour 1984: 173)

Glymour thinks that science provides such good explanations and some of them posit unobservables:

sometimes the best explanation does go well beyond what is observed or observable ... the same features of inference which lead to general conclusions about the observable also lead in other contexts to determinate conclusions about the unobservable. (1984: 175)

Glymour sees such scientific explanations positing unobservables as providing the case for realism. In effect, he is urging BA. He never mentions NMA.

Salmon: In "Scientific Explanation and the Causal Structure of the World" (1984: 213-227), in (Leplin 1984) once again, Salmon offered what he describes as "an empirical approach" to scientific realism, considering "the evidence and arguments that convinced scientists of the reality of unobservable entities." He finds Jean Perrin's argument for the existence of atoms and molecules "the most clear and compelling example" (Salmon 1984: 213-214). The empirical arguments that Salmon has in mind are what I am calling abductions. In effect, Salmon is urging BA. ${ }^{11}$

I noted in section 2 that BA is a wholesale argument for realism based on retail arguments. The authors we have been discussing provide examples of the sort of retail arguments in question. Thus, McMullin gives examples from

\footnotetext{
${ }^{10}$ McMullin uses the term "retroduction," not "abduction," for this form of argument.

${ }^{11}$ Achinstein 2002 is a defense of Salmon's argument. (Thanks to Greg Frost-Arnold for drawing these two works to my attention.)
} 
geology, genetics, chemistry (1984: 27-28), astrophysics, and cosmology (1991: 101). Salmon gives a detailed presentation of the just-mentioned argument by Perrin for the existence of atoms and molecules (1984: 213-227). Glymour (1984: 175-177) gives four examples: Copernican explanations of planetary regularities, the Daltonian explanation of the law of definite proportions, the general relativistic explanation of Mercury's perihelion and of deflection of starlight near the sun, and Spearman's explanation of correlations among intelligence tests. Glymour nicely remarks that these cases "have no uniform connection with distinctions between what is observable and what is not" (1984: 177). The realist literature provides plenty of other examples; for example, Richard Miller has a detailed discussion of the cases of microbes (1987: 465-469) and molecules (1987: 470-482). And, Hacking, in effect, indicates a way to find many such arguments:

Experimental work provides the strongest evidence for scientific realism . . . because entities that in principle cannot be "observed" are regularly manipulated to produce a new phenomen[on] and to investigate other aspects of nature. (1983:262)

The delightful slogan for this defense of realism, arising from Hacking's discussion of electrons (1983: 24), is: "If you can spray them, they're real." This sort of experimental work yields thousands of abductions. ${ }^{12}$

In sum, according to BA, SR and SSR, which are cautious summaries of the commitments of well-established current theories, best explain observed phenomena in virtue of scientific abductions, of the sort just mentioned, that make those theories well-established. The strength of BA lies simply in those scientific abductions.

BA, found at least in works by Devitt, Glymour, McMullin, Salmon, and Smart, ${ }^{13}$ and implicit, I would say, in the practices of science itself, seems to have no place in the current debate about scientific realism. The literature did not critically assess BA and find it wanting. Rather, the literature almost entirely ignored BA in favor of NMA. Thus, André Kukla, in Studies in Scientific Realism, claims: "The bedrock of the case for scientific realism is the argument from the success of science" (1998: 22). The only sign of BA in this book that aims "to provide a systematic and exhaustive survey of all the important considerations that bear" on scientific realism (1998: vii) is, in effect, a brief mention citing Glymour (1984). The argument is dismissed in a sentence (Kukla 1998: 82). Stathis Psillos' similarly thorough Scientific Realism (1999) has a chapter entitled, "In Defence of Scientific Realism." It is all about NMA.

${ }^{12}$ Hacking strangely does not regard them as abductions; for discussion, see Devitt 1984: 112-113.

13 Perhaps there are signs of it in Levin 1984 also. 
BA goes unmentioned and none of the works in which it is to be found is cited. Michel Ghins notes that NMA is "considered by many to be ... the major argument in favour of scientific realism" (2002: 121). In the critical discussion that follows, again, BA goes unmentioned and the BA works uncited. ${ }^{14}$ More recently, an article by David Harker discussing "the most influential arguments for scientific realism" (2010: 192) also does not mention BA nor any of those works. ${ }^{15}$ Yet, I suggest, what is being thus ignored is the core underlying reason for scientific realism. It is, in McMullin's words, "the best case for scientific realism."

It is time to show this by comparing BA with NMA. The differences between them are subtle, but I think that they are very significant. They give realists good reason to focus on defending BA, not NMA.

\section{THESIS IV: NMA IS DUBIOUS BUT BA IS GOOD: SO THE DIFFERENCE BETWEEN THEM IS SIGNIFICANT}

The strength of NMA is that it offers an explanation of success where antirealism's explanation - in effect, theories are successful because they are empirically adequate - is, in my view (Devitt 2005/2010: 75), shallow to the point of nonexistence. ${ }^{16}$ But Laudan (1981) has famously posed a problem for NMA by producing a list of past theories - phlogiston theory is a favorite that were successful but are now thought not to be approximately true. So, the approximate truth of a theory was often not the explanation of its success. For years, the realist strategy in response has been to chip away at Laudan's criticism. Thus, the success of a theory can be challenged: although a past

14 Ghins does talk approvingly of arguments for the truth of theories like the arguments that underlie BA. However, he does not take these as arguments for scientific realism (2002: 129-131).

${ }^{15}$ My attention has been drawn to Penelope Maddy's nice discussion of scientific realism (2007: 305-313). In arguing against van Fraassen's constructive empiricism, Maddy, in effect, proposes BA. Her discussion is not mentioned by Harker either. And she does not mention the earlier presentations of BA. It is also interesting that none of the 1984 presentations of BA mentions Smart 1982. And McMullin 1991 does not mention any of those works by other authors. Musgrave 1988 does not mention any of these works either.

${ }^{16}$ Van Fraassen (1980: 39) famously offered a Darwinian rival to NMA's explanation. I agree (1984/1991: 116) with those like Peter Lipton (1991: 170-172) who argue that this explanation is not relevant because it is not explaining the same thing as NMA. It is not explaining why those particular theories are successful. It is also worth noting, as Elay Shech pointed out to me, that BA's explanation of the observable phenomena does not face even a putative Darwinian rival, a nice sign that BA really is different from NMA. 
theory was thought to be successful, it was not really so (McAllister 1993). It can be argued that a theory was not, in the appropriate sense, well-established and hence not the sort that the realist is committed to; or that some entities it posited were not essential to its success (Kitcher 1993: 140-149); or that although there was a deal of falsity in these theories there was a deal of truth too (Worrall 1989). Psillos' neat idea of "divide et impera" has been influential (1999). But the chipping-away strategy still leaves worries. Thus, unless the criterion of success is put so high that not even well-established contemporary theories will qualify, some theories on Laudan's list will surely survive. And many of those were surely well-established and likely had essential parts that we now think false. But, more important than these worries, NMA has a deep problem that this strategy does not address.

Realists should not have needed Laudan's list to make them aware that false theories, even false essential parts of theories (take this qualification as read in what follows), can be successful and likely sometimes have been. Indeed, NMA's cautious talk of what is typically the case acknowledges that the explanation of a theory's success is sometimes not that the theory is approximately true. And realists should accept that some well-established current theories may be of that sort. Suppose that $T$ was such a theory. What should a realist say about T's success? She should say that T's success is to be explained by currently unknown facts about unobservables: by unobservables not posited by $T$ and/or by unobservables posited by $T$ but with properties not envisaged by $T$. And the realist expects that these facts will later be discovered by a successor theory. ${ }^{17}$ All well and good, except that this expectation does not help NMA as an argument for SSR. For it provides no reason to believe in the approximate truth of that current theory, $T$, nor even in its entities. So, in effect, NMA presumes that our current theories are typically unlike $T$ in that their success is explained by their own approximate truth and does not await explanation by the approximate truth of as yet unconceived future theories..$^{18}$ But what justifies this presumption?

Realists do not seem to have sufficiently appreciated how worrying this question is for NMA. ${ }^{19}$ Assessing abductions is a tricky business, of course; we are a long way from an algorithm for it. But careful thought about this question seems to me to show that NMA's abduction is dubious.

\footnotetext{
${ }_{17}$ I made an answer along these lines (Devitt 1984/1991: 114; 2005/2010: 74-75).

${ }^{18}$ If the only alternative to NMA's explanation of the success of $T$ was the antirealist's non-explanation, then the realists' "no-miracles" rhetoric might be appropriate. However, given the real possibility that the success of $T$ might be explained by some other theory, the rhetoric seems rather inflated.

19 I am one who didn't (Devitt 2005/2010: 75).
} 
Realists and antirealists alike should agree that there is an unobservable world of some sort. It is then obvious that, if the success of our well-established current theories is to be explained at all, it is to be explained by true theories of that unobservable world. NMA's claim that those current theories themselves typically explain this success presumes that those theories are typically among the (at least approximately) true ones. For NMA to be sound, given what is needed for a good abduction, that presumption has to be, as I put it in discussing abduction in section 4, plausible relative to background knowledge, and it is has to be better than any alternative that is likely, given what we know. But that seems to require some reason, independent of NMA, for supposing that those current theories are typically among the approximately true ones - that is, for supposing SSR. For those current theories are our only available source of information about the unobservable world and hence our only potential background knowledge relevant to the assessment of both the plausibility of NMA's explanation and the likelihood of a better one in future. So, if we lacked any independent reason for confidence in the theories, we would be totally ignorant of the unobservable world and hence have no idea what aspects of it might plausibly be thought to be responsible for the success of the theories. Rather, we should wonder whether aspects described by those current theories are typically responsible, sometimes responsible, or never responsible for their success. Without the independent reason, one of these alternatives should not seem more plausible than another. All abductions are fallible, of course, but this problem for NMA seems much deeper. And NMA is not made good by the present lack of an actual alternative explanation of success. Absent evidence that our theories are revealing the nature of the unobservable world, we should simply suspend judgment on what explains their success. Take any one of these current theories. Absent an independent reason for supposing that such a theory is typically approximately true - that is, for supposing SSR - the explanation of its success must await the development of new theories that we will be independently justified in believing. Now I think that we do have the needed reason for SSR - see below - but the problem for NMA is that NMA does not provide it. Rather, NMA, in effect, seems to presume SSR, just what it is trying to establish, and not to be a good abduction. ${ }^{20}$

To say that NMA is not a good abduction to SSR is not, of course, to say that SSR is not a good explanation of success. Still SSR is only a good explanation if we have some reason, independent of NMA, for believing that SSR is

${ }^{20}$ NMA is often accused of question begging because of its use of abduction. I think that this accusation is false (Devitt 2005/2010: 76). 
true. ${ }^{21}$ And, of course, if we have that needed reason, then we have already established SSR and have no need of NMA. NMA seems to be not only a dubious argument for realism but also superfluous.

So what reason do we have for believing SSR? NMA's talk of observational success prompts an answer: we should believe that well-established current theories are typically approximately true because they are observationally successful. The realist, in urging NMA, made the mistake of claiming that SSR is true because it explains success. The realist should rather have claimed that SSR is true because it is successful. Now this is an improvement over NMA because it has no question-begging air about it. But it still fails as an argument for realism. The problem is that making true observational predictions is not generally sufficient ground for the approximate truth of theories and hence for SSR; theories also need to explain what they predict.

That brings us to BA. We should believe SSR - that typically our wellestablished current theories are approximately true - because they best explain the observed phenomena. This abduction is fallible like any other, but it is good. Its goodness comes from the strength of the scientific abductions on which it is based, abductions involving explanations of the sort mentioned in section 5 .

NMA looks in the wrong place to justify realism. The goodness of NMA's explanation of success depends on the goodness of BA's abduction to scientific realism.

Now, of course, switching from NMA to BA does not make the familiar objections to scientific realism go away. I have already noted (section 4) that some philosophers reject abduction altogether. Some who accept abduction will object to relying on the scientific abductions that underpin BA. Van Fraassen $(1980,1989)$ argues that science supports a commitment only to claims about observables. Relatedly, it has been common to think that scientific realism fails because of a doctrine of "empirical equivalence" that shows theories to be underdetermined by all possible evidence. Most worrying of all, in my view, is "the pessimistic meta-induction." The defense of realism requires that all these objections be addressed. ${ }^{22}$ This is not the place to do

${ }^{21}$ Even then, this explanation has a disappointing air of triviality, as I have pointed out (Devitt 1984/1991: 114). It is not hard to locate the source of this air. Suppose that a theory says that $S$. Now it is near tautological that if $S$, then the world (as a whole) is as if $S$. So, a fortiori, the observable world is as if $S$. This is rather boring.

${ }^{22}$ Perhaps not the rejection of abduction. (1) A defense of abduction is not required in responding to a critic of BA who relies on abduction to support her realism about observables (Smart 1982: 366, McMullin 1984: 15, 33-34; 1991: 102, Boyd 1984: 65-75). (2) Should a critic's objection to BA be a total rejection of abduction, then the realist might apply a quite general realist strategy for responding to critics (Devitt 2005/2010: 76). The critic 
so. ${ }^{23}$ But a consequence of my argument is that the realist should defend $B A$, not NMA, from these familiar objections. The realist needs to defend abductions like the earlier-mentioned one by Perrin to the existence of atoms and molecules. For those abductions provide the case for scientific realism.

The most important reason for preferring BA to NMA is the one we have just discussed, but there is another.

\section{THESIS V: \\ A META-SCIENTIFIC "PHILOSOPHICAL LEVEL" ARGUMENT FOR REALISM LIKE NMA IS NEITHER NEEDED NOR DESIRABLE}

NMA is a wholesale argument explaining the general success of well-established current scientific theories. So it seems open to Arthur Fine's complaints about realist philosophers operating at a level above science (1986a). I have pointed out that NMA rests on retail arguments, abductions of the form: (the approximate truth of) $T_{n}$ explains the success of $T_{n}$. But this does not save NMA from Fine's complaints because these are not the sort of abductions that we find in science; they are "philosophical" abductions. In contrast, BA rests on abductions of the form: $T_{n}$ best explains $P_{n}$ - just the sort of abduction that we find in science (see section 5). As McMullin says in response to Fine (1991), "the argument is properly carried on at one level only, the level of the scientist" (1991: 104). ${ }^{24}$ Now, of course, in urging BA, McMullin and others are standing back from science and "doing philosophy." Thus, we judge from what scientists say and do that they draw realist conclusions from the findings that establish scientific theories. In any case, and crucially, we argue that realist conclusions should be drawn from those findings, for they constitute

in question must, of course, use some method of ampliative inference other than abduction to support her beliefs about the observable world. The realist might then be able to show that this method also supports beliefs about unobservables and hence realism. But I rather doubt that the realist could.

23 But I have responded elsewhere to the rejection of abduction (Devitt 2005/2010: 76-77, see also 2011a/2010: 277-283); to van Fraassen (Devitt 1984/1991: 137-154); to the underdetermination argument (1984/1991: 117-121; 2005/2010: 79-86; 2010: 91-93); to the pessimistic meta-induction (1984/1991: 162-165; 2005/2010: 89-90; 2010: 96-98; 2011b).

${ }^{24}$ Relatedly, BA is not open to the charge that Greg Frost-Arnold levels at NMA: "Scientific realism (as it appears in the NMA) generates no new predictions and does not unify any apparently disparate claims" (2010: 36). Scientific realism, as it appears in the $\mathrm{BA}$, does generate these because the scientific abductions on which it rests generate them. I think that Frost-Arnold would agree (2010: 53). 
good abductions for realism about unobservables.25 Still this "philosophical" case for realism is not in any interesting sense at a different level from science. It rests on those scientific abductions not on some special philosophical abduction that is supposed to justify the conclusions of science. (I assume that that was why I called it "basic.") Hilary Putnam once said that realism takes science at "face value" (1978: 37). BA is in the spirit of that remark.

This is the appropriate moment to address a question raised at the beginning: Why has BA been ignored in the literature? Doubtless part of the answer is that philosophers have not clearly distinguished BA from NMA; consider Smart, for example (section 5). But my experiences in urging BA make me think that the answer is also to be found in the very reason that BA is not open to Fine's complaints. Simply because BA is not at a different level from science, because it is so basic, philosophers think that it is not doing the required philosophical job. ${ }^{26}$ For that job precisely is to come up with some meta-scientific argument that is indeed intended, as Fine suspects, to justify our reliance on science. NMA is an example of such an argument. Arguments appealing to causal theories of reference or correspondence theories of truth are other examples. This hankering after a justification at a philosophical level above science is understandable - it's hankering after a job for philosophers, after all! - but naturalists should think it is quite mistaken. Scientific realism is committed to a view of the existence and nature of atoms, viruses, photons, and the like. There is no way to find out about this unobservable world other than by looking to science. Indeed, for that reason, naturalists are likely to think that there should not really be a philosophical issue of scientific realism. In sum, the argument for realism should rest on science, as BA does. Nothing meta-scientific is needed or desirable.

Philosophers have, of course, raised doubts about the unobservable world of science, doubts of the sort noted in section 6 , and have thus created a philosophical issue. But the right way to respond to these doubts is by defending BA from them, not by attempting to come up with a "philosophical" argument for scientific realism like NMA. The argument for realism is BA. The philosophical task for the scientific realist is to respond to arguments against realism insofar as they appear to undermine BA.

NMA's meta-scientific level case for scientific realism is that SSR explains why scientific theories are observationally successful. In section 6, I drew attention to and preferred, but did not embrace, what is in fact a scientific-level

${ }^{25}$ Given the roles of idealizations and models in science, emphasized to me by Peter Godfrey-Smith, drawing those conclusions can sometimes be a rather subtle business, of course.

${ }^{26}$ See, for example, Kukla's earlier-mentioned swift dismissal of the argument (1998: 82). 
correlate of NMA: the case for realism is that the theories are observationally successful. This prompts a further thought. Just as the meta-scientific NMA has this scientific correlate, the scientific BA has a meta-scientific correlate. Instead of taking scientific realism to be justified by its explanatory success, as BA does, we could take it to be justified by its explanation of this explanatory success, perhaps as well as, of its predictive success. That meta-scientific correlate is, in fact, the version of NMA that we noted but set aside in section 2. It is urged by Doppelt: "realists' explanation of the success of our best theories is incomplete if it does not explain their explanatory as well as their predictive success" (2007: 99). He urges this version because he emphasizes the importance to realism of the explanatory virtues of theories (Doppelt 2007: 97). From the perspective of the present paper, Doppelt has made the wrong response to what he rightly emphasizes, for this version of NMA seems to suffer from the same faults as the standard version we have been discussing. The right response to what he emphasizes is BA. The case for realism is that it is explanatorily successful not that it explains explanatory success.

In sum, the objections to NMA that we have presented suggest that it is a dubious argument for SSR. These objections do not count against BA. So, I suggest that realists should focus on defending BA, not NMA.

\section{CONCLUSION}

Why believe in scientific realism? The answer that overwhelms the literature is NMA: realism best explains the observational success of scientific theories. Yet, more than thirty years ago, another argument, BA, was proposed by Devitt, Glymour, McMullin, Salmon, and Smart: realism best explains the observed phenomena. BA has not been directly confronted but almost entirely ignored (Theses I, II, and III). In this paper, I have argued that BA is a good argument for realism whereas NMA is a dubious one (Thesis IV). In light of this, realists should focus on defending BA, particularly from the pessimistic meta-induction. I don't suggest that this defense is easy (and have made no attempt at it here).

Why has BA been ignored? I have suggested that philosophers find it too close to science, "not philosophical enough," to be interesting. This hankering after a justification for realism from outside science is mistaken (Thesis V). 


\section{BIBLIOGRAPHY}

Achinstein P. (2002), "Is there a Valid Experimental Argument for Scientific Realism?," Journal of Philosophy 49, 470-495. https://doi.org/10.2307/3655684

Boyd R. N. (1984), “The Current Status of Scientific Realism” [in:] Leplin 1984: 41-82.

Brown J. R. (1994), Smoke and Mirrors: How Science Reflects Reality, New York: Routledge. https://doi.org/10.4324/9780203305355

Devitt M. (1984), Realism and Truth, 1st ed., Oxford: Basil Blackwell. [2nd ed., 1991. Reprinted with new Afterword, Princeton University Press, Princeton 1997. Citations are to the 2nd ed.]

Devitt M. (2001), "Incommensurability and the Priority of Metaphysics" [in:] Incommensurability and Related Matters, P. Hoyningen-Huene, H. Sankey (eds.), Dordrecht: Kluwer, 143-157. [Reprinted with Postscript in Devitt 2010: 99-120.] https://doi.org/ 10.1007/978-94-015-9680-0_5

Devitt M. (2005), "Scientific Realism" [in:] The Oxford Handbook of Contemporary Philosophy, F. Jackson, M. Smith (eds.), Oxford: Oxford University Press, 767-791. [Reprinted with Postscript in Devitt 2010: 67-98. Citations are to Devitt 2010.] https://doi.org/10.1093/oxfordhb/9780199234769.003.0026

Devitt M. (2010), Putting Metaphysics First: Essays on Metaphysics and Epistemology, Oxford: Oxford University Press. https://doi.org/10.1093/acprof:oso/9780199280803. 001.0001

Devitt M. (2011a), "No Place for the A Priori” [in:] What Place for the A Priori?, M. J. Shaffer, M. L. Veber (eds.), Chicago-La Salle: Open Court, 9-32. [Reprinted in Devitt 2010: 271279. Citations are to Devitt 2010.] https://doi.org/10.1093/acprof:oso/ 9780199280803. 003.0014

Devitt M. (2011b), “Are Unconceived Alternatives a Problem for Scientific Realism?,” Journal for General Philosophy of Science 42, 285-293. https://doi.org/10.1007/s10838-0119166-9

Doppelt G. (2007), "Reconstructing Scientific Realism to Rebut the Pessimistic Metainduction," Philosophy of Science 74, 96-118. https://doi.org/10.1086/520685

Dummett M. (1978), Truth and Other Enigmas, Cambridge, MA: Harvard University Press.

Fine A. (1986a), The Shaky Game: Einstein, Realism, and the Quantum Theory, Chicago: University of Chicago Press.

Fine A. (1986b), "Unnatural Attitudes: Realist and Instrumentalist Attachments to Science," Mind 95, 149-177. https://doi.org/10.1093/mind/XCV.378.149

Fine A. (1991), "Piecemeal Realism," Philosophical Studies 61, 79-96. https://doi.org/10.1007/ BFoo385834

Frost-Arnold G. (2010), "The No-Miracles Argument for Realism: Inference to an Unacceptable Explanation,” Philosophy of Science 77, 35-38. https://doi.org/10.1086/ 650207

Gauker C. (2006), "Scientific Realism as an Issue in Semantics" [in:] Truth and Realism, P. Greenough, M. Lynch (eds.), Oxford: Oxford University Press, 125-136. https://doi.org /10.1093/acprof:0so/9780199288878.003.0007

Ghins M. (2002), "Putnam's No-Miracle Argument: A Critique?" [in:] Recent Themes in the Philosophy of Science: Scientific Realism and Commonsense, S. Clarke, T. Lyons (eds.), Dordrecht: Kluwer, 121-138. https://doi.org/10.1007/978-94-017-2862-1_6

Glymour C. (1984), “Explanation and Realism” [in:] Leplin 1984, 173-192. 
Hacking I. (1983), Representing and Intervening: Introductory Topics in the Philosophy of Natural Science, Cambridge: Cambridge University Press. https://doi.org/10.1017/CBO 9780511814563

Harker D. (2010), "Two Arguments for Scientific Realism Unified," Studies in History and Philosophy of Science 4, 192-202. https://doi.org/10.1016/j.shpsa.2010.03.006

Kitcher P. (1993), The Advancement of Science: Science without Legend, Objectivity without Illusions, New York: Oxford University Press.

Kukla A. (1998), Studies in Scientific Realism, New York: Oxford University Press.

Laudan L. (1981), “A Confutation of Convergent Realism," Philosophy of Science 4, 19-49. https://doi.org/10.1086/288975

Leplin J. (ed.) (1984), Scientific Realism, Berkeley: University of California Press.

Levin M. (1984), “What Kind of Explanation is Truth?” [in:] Leplin 1984, 124-139.

Lipton P. (1991), Inference to the Best Explanation, London: Routledge.

McAllister J. W. (1993), "Scientific Realism and Criteria for Theory-Choice," Erkenntnis 38, 203-222. https://doi.org/10.1007/BFo1128980

McMullin E. (1984), “A Case for Scientific Realism” [in:] Leplin 1984, 8-40.

McMullin E. (1991), “Comment: Selective Anti-realism,” Philosophical Studies 61, 97-108. https://doi.org/10.1007/BFoo385835

Maddy P. (2007), Second Philosophy: A Naturalistic Method, Oxford: Oxford University Press. https://doi.org/10.1093/acprof:oso/9780199273669.001.0001

Magnus P. D., Callender C. (2004), "Realist Ennui and the Base Rate Fallacy," Philosophy of Science 71, 320-338. https://doi.org/10.1086/421536

Miller R. W. (1987), Fact and Method: Explanation, Confirmation and Reality in the Natural and Social Sciences, Princeton: Princeton University Press.

Musgrave A. (1988), “The Ultimate Argument for Scientific Realism” [in:] Relativism and Realism in Sciences, R. Nola (ed.), Dordrecht: Kluwer, 229-252. https://doi.org/ 10.1007/978-94-009-2877-0_10

Psillos S. (1999), Scientific Realism: How Science Tracks Truth, London: Routledge.

Putnam H. (1975), Mind, Language, and Reality: Philosophical Papers, vol. 2, London: Cambridge University Press. https://doi.org/10.1017/CBO9780511625251

Putnam H. (1978), Meaning and the Moral Sciences, London: Routledge \& Kegan Paul.

Putnam H. (1987), The Many Faces of Realism, LaSalle: Open Court.

Salmon W. C. (1984), Scientific Explanation and the Causal Structure of the World, Princeton: Princeton University Press.

Smart J. J. C. (1963), Philosophy and Scientific Realism, London: Routledge \& Kegan Paul.

Smart J. J. C. (1968), Between Science and Philosophy: An Introduction to the Philosophy of Science, New York: Random House.

Smart J. J. C. (1982), "Difficulties for Realism in the Philosophy of Science" [in:] Logic, Methodology, and Philosophy of Science VI: Proceedings of the Sixth Annual Congress of Logic, Methodology, and Philosophy of Science, Hannover 1979, L. J. Cohen, J. Łoś, H. Pfeiffer, K. P. Podewski (eds.), Amsterdam: North-Holland, 363-375. https:// doi.org/10.1016/So049-237X(09)70206-X

van Fraassen B. C. (1980), The Scientific Image, Oxford: Clarendon Press. https://doi.org/ 10.1093/0198244274.001.0001

van Fraassen B. C. (1989), Laws and Symmetry, Oxford: Clarendon Press. https://doi.org/ 10.1093/0198248601.001.0001 